\title{
Stormwater quality calibration by SWMM: A case study in Northern Spain
}

\author{
Javier Temprano* ${ }^{1 *}$ Óscar Arango ${ }^{1}$, Juan Cagiao ${ }^{2}$, Joaquín Suárez ${ }^{2}$ and Iñaki Tejero ${ }^{1}$ \\ ${ }^{1}$ Departamento de Ciencias y Técnicas del Agua y del Medio Ambiente, Ingeniería Ambiental, Universidad de Cantabria, Tanos, 254, \\ E-39316 Torrelavega (Cantabria), Spain \\ ${ }^{2}$ Grupo de Ingeniería del Agua y del Medio Ambiente. E. T. S. Ingenieros de Caminos, C. y P., Universidade da Coruña, Campus de \\ Elviña, s/n, E-15192 La Coruña, Spain
}

\begin{abstract}
This article presents an application of the Storm Water Management Model (SWMM) in order to predict the pollution in rainy weather in a combined sewer system catchment in Santander, Spain. Suspended solids (SS), chemical oxygen demand (COD) and total Kjeldahl nitrogen (TKN) were measured at the exit of the catchment and these parameters were used for the calibration and validation of the model. The process of hydraulic and quality calibration is described and the values of the adjusted parameters are presented, comparing them with those obtained from other studies. The calibrated model simulated accurately the hydrograph's shape and the time of presentation of the peak flows. The accuracy of adjustment of the volume was $96 \%$. As for the quality validation, the accuracy of adjustment among the total simulated loads of SS, COD and TKN, and those measured at the end of the rainfall events were 93,95 and $78 \%$ respectively, confirming the accurate confirming the relative accuracy of the model in the prediction mode. The phenomenon of the first flush was analysed, and it was determined that 65 , 57 and $54 \%$ of the polluting loads of COD, SS and TKN respectively, were swept along by the first $30 \%$ of the volume in the rainfall events used for the calibration of the model.
\end{abstract}

Keywords: calibration, SWMM, sewage, first flush, stormwater runoff, event mean concentration, urban areas

\section{Introduction}

Urban runoff is one of the factors which has the most influence on the water quality of water bodies (Characklis and Wiesner, 1997; Tsihrintzis and Hamid, 1998). The determination of the even mean concentration (EMC) is an approximation method, which is used to study its effects (Huber, 1992; Novotny and Olem, 1994; Charbeneau and Barrett, 1998).

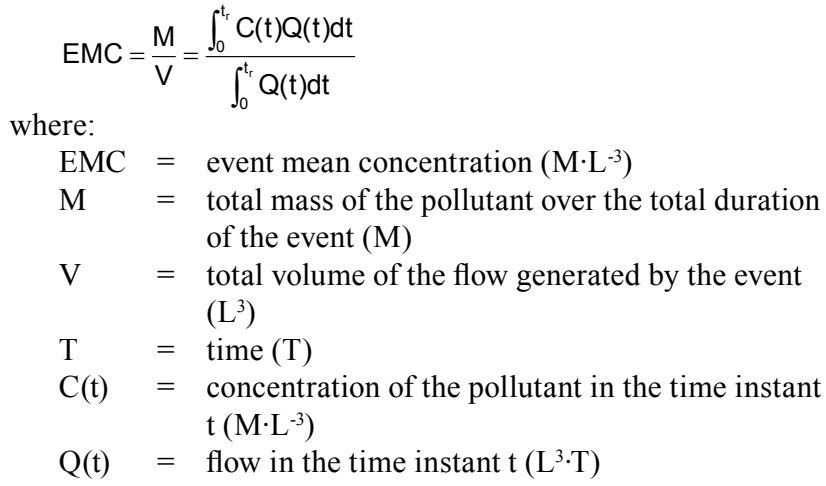

An approximation of this type has the advantage of simplicity. However, in some cases, it is necessary to resort to all the information obtained in the hydrographs and pluviographs generated by one rainfall event. On these occasions the existence of a hydraulic model as well as the calibration and validation of the catchment area of the study, signifies great help for the design

* To whom all correspondence should be addressed.

证 +34-942-846538; fax: +34-942-846503;

e-mail:temprani@unican.es

Received 10 May 2005; accepted in revised form 20 September 2005. of the regulation structures of the combined sewer system (Temprano and Tejero, 2002).

On the other hand, several authors (Gupta and Saul, 1996; Deletic, 1998) suggest that the most polluted part and therefore, the most adverse for the receiving water, is the one generated at the start of a rainfall event. Therefore the study of the initial flow of precipitation acquires great importance, especially when studying the combined sewer overflows generated in the storage structures located downstream of the combined sewer system (Diaz-Fierros et al., 2002). Nevertheless, there are authors (Cristina and Sansalone, 2003) who suggest that the approximation of the first flush is not enough, since at least with respect to the separation of particles, it would be necessary to retain the ones generated by the precipitation as a whole and not only those which would correspond to the first flush.

The above discussion reveals the need for knowing in advance the quantity and quality of the mixed waters in rainy weather in combined sewer systems, in order to estimate their effects at the very moment when the overflows take place, and for the design and the proper performance of the combined sewer system, in terms of the quality criteria of the receiving waters. Several mathematical simulation models have been developed for this purpose; the most well-known are: SWMM (Huber and Dickinson, 1988), STORM (Hydrologic Engineering Center, 1977), DR3M-QUAL (Alley and Smith, 1982), MOUSE (Danish Hydraulic Institute, 1990). As discussed by Zoppou (2001) there is a great variety of models for this type of simulation.

The Storm Water Management Model (SWMM version $4.4 \mathrm{~h}$ ) was used here (Huber and Dickinson, 1988), as it is one of the most complete and widely used throughout the world. The SWMM allows the simulation of flows and polluting loads of urban runoff as well as their carriage through the combined sewer system. This is not only for a single rainfall event, but 
also for long periods (continuous simulation). It presents several options to simulate the build-up and wash-off of the pollutants in the catchment area, and different conditions in the combined sewer system too.

In this article, the hydraulic and quality calibration and validation process of a series of rainfalls for a catchment area of the combined sewer system type in Santander (Spain) is shown. The analytical parameters studied were suspended solids (SS), chemical oxygen demand (COD) and total Kjeldahl nitrogen (TKN). The study was carried out over the period January to November 2001.

The aims of the study were to:

- Make a hydraulic and quality calibration and validation of the performance of the catchment area which is being studied, considering a series of rainfalls

- Evaluate the effect of the first flush.

The accuracy of the adjustment with respect to the established aims for the calibration, was superior to $95 \%$, showing the good prediction capability of the model. The phenomenon of the first flush in the rainfall events used for the calibration was observed and the simulation could also be accurately adjusted to the tendency of the pluviographs.

\section{Methodology}

\section{Experimental site}

The catchment area studied is situated in the north-western part of the city of Santander (Spain). It is a single-family residential urban area, and has a population density of 100 inhabitants/ha. However, there is an approximate increase of $60 \%$ in summer, owing to the tourist activity in the city. A light business activity because of the presence of some hotels and restaurants is also observed. The catchment area has a surface of 56 ha and an impermeability percentage of $34 \%$.

\section{Discretisation of the catchment area}

A detailed discretisation of the catchment area was made, by using maps and by conducting a wide topographic campaign. First, all the catch-basins and manholes of the combined sewer system drainage and the combined sewer of the catchment area were located on the map. After that, the draining area was delimited to each catch-basin according to the topographic lines of the land. As a result of this, there were a total of 139 subcatchments. In order to obtain better precision with the discretisation, and with the purpose of achieving high-quality calibration, the total area of the streets was also subdivided into small sections, each ending in a manhole; this way arriving at 107 additional subcatchments (which from now on will be called "streets").

With a total of 246 subcatchments, it was possible to use two different systems of accumulation of dust and build-up in the runoff block of the SWMM. One of them was used depending on the surface (mass per surface unit) for the subcatchments case, and the other was used depending on the length of the curbs (mass per unit of length of curb) for the streets.

The slope of the subcatchments was determined by an adjustment between the slope of the land and the corresponding area of roofs in each one of them, whereas the slope of each street was measured in situ. With respect to the width, a first estimation was made by measuring an average width on the map in a perpendicular direction to the flux line for each subcatchment. In Table 1, the characteristics that were obtained as a result of the

\begin{tabular}{|l|l|l|}
\hline \multicolumn{3}{|c|}{ TABLE 1 } \\
\hline \multicolumn{2}{|c|}{$\begin{array}{c}\text { Physical characteristics of the discretised } \\
\text { subcatchments }\end{array}$} \\
\hline Characteristics & Subcatchments & Streets \\
\hline Total area (ha) & 37.3 & 18.9 \\
\hline Average area $\left(\mathrm{m}^{2}\right)$ & 3213 & 1080 \\
\hline Average width (m) & 44.9 & 15.9 \\
\hline Average slope (\%) & 13.1 & 5.1 \\
\hline Average impermeability (\%) & 17.7 & 100 \\
\hline
\end{tabular}

discretisation work are summarised, which are inserted as initial data before the calibration process.

\section{Description of the combined sewer system}

It is a combined sewer system composed of sewers and manholes which are placed in a distance that may vary between 50 and $100 \mathrm{~m}$. The primary sewers are mostly concrete tubes of a circular section with diameters between 200 and $400 \mathrm{~mm}$. However, there are also three sections of sewers with an ovoid shape. The catchment area is covered along its north area by a main sewer which is circular and has a diameter of $800 \mathrm{~mm}$ in the initial section, and $1100 \mathrm{~mm}$ in the final section. The estimated length of this sewer is $1.6 \mathrm{~km}$ up to the downstream point, where the measuring and sampling equipment was placed. The average slope of the combined sewer system, measured for each section between two consecutive manholes, turned out to be $6.6 \%$ and the total length of the primary sewers was $6.9 \mathrm{~km}$. A simplified sketch of the combined sewer system can be observed in Fig. 1.

\section{Description of the rainfall events}

Three rainfall events occurred while the project was being undertaken. For the first two events, water quality and flow data were collected at the exit of the catchment, whereas for the third event, only flow was measured (see Table 2).

\section{Sampling and measuring programme}

Rainfall, flow and the taking of samples for the analysis of the quality of the water of the catchment area were measured over 6 different campaigns between February and November in 2001, as shown in Table 3. Owing to location conditions and easy access, a manhole located in the main sewer at the exit of the catchment area was selected (see Fig. 1), where the following equipment was installed:

- Flow meter made by American Sigma, model 950. It measures the level of water in the sewer by a bubbler, and the flux velocity as well, by means of a Doppler sensor. Registers were obtained every $5 \mathrm{~min}$

- Device for the taking of samples made by American Sigma, model 900 MAX. interconnected with the flow meter.

- Rain gauge manufactured by American Sigma, of the balance bowl type. It measures and registers automatically the volume of precipitation at intervals of $5 \mathrm{~min}$, depending on the number of times that the bowl is emptied in this period. The volume of the bowl was $0.25 \mathrm{~mm}$.

\section{Quality parameters analysed and techniques used}

Three pollutants were analysed and used for the calibration of the model: suspended solids (SS), chemical oxygen demand (COD) and total Kjeldahl nitrogen (TKN), which were selected 


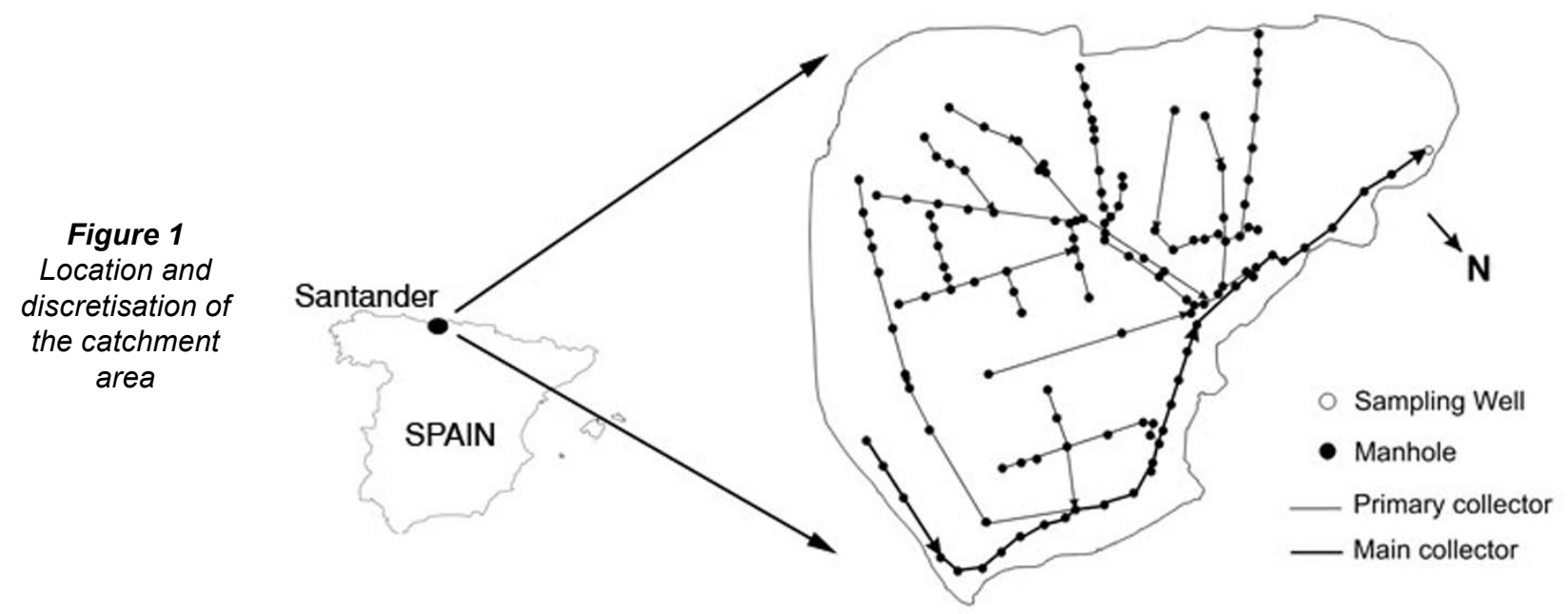

because they are often used as indicators of the quality of the water as well as for their impact in the receiving water. The analytical methods followed the suggestions described by Standard Methods (1998), COD by digestion and by titrimetry (5220-C), SS by gravimetry $(2540-\mathrm{D})$ and TKN by digestion and distillation (4 500- $\mathrm{N}_{\text {org }} \mathrm{C}$ ).

\section{Description of the SWMM model}

The model comprises functional blocks, which are co-ordinated by an executive block. These can be sequentially or separately activated, depending on the needs of the user. The runoff block, as well as the transport block, was used for this study. The runoff block simulates the hydrographs for each subcatchment, according to a hyetograph of entrance and the physical characteristics of the subcatchment, including area, width, average slope, grade of impermeability, resistance factor for the surface runoff, infiltration parameters and surface storage. Pollutographs are simulated according to the runoff volume and to the previous conditions of the catchment area, such as dry weather days, cleaning of streets and the use of the land, among others. The hydrological estimation in the runoff block is based on the theory of non-linear storage. The infiltration losses are estimated by using the Horton equation or the Green-Ampt equation. For this study, the Horton equation was used, as it only requires three parameters, quite well-defined in the bibliography, and because the physical parameters of the Green-Ampt equation are unknown for the area. The transport block simulates the propagation in the combined sewer system of the surface storm water hydrograph, as well as the transport of the pollutants. It also allows the simulation of the dry weather flow, which is entered into the program as a constant value. The estimation of flows in the transport block is made by

cascade, starting at the upstream pipes and going downstream by using the kinematic wave formula. The sedimentation processes of particles contained in the dry weather flow, and the later resuspension during rainy weather are also taken into account in the model although the routine that is used here represents a broad approximation of the real phenomena of sedimentation and transportation in the combined sewer system.

\section{Calibration procedure}

Liong et al. (1991) subdivided the calibration parameters of the runoff block of the SWMM into two groups: the traditional parameters, which include the roughness coefficients, the storage in surface depressions and the infiltration parameters; and non-traditional parameters whose values are obtained from the measures and/or the interpretation of the information available. The values which come from this last group, are considered fixed; however, owing to the margin of relative error, which can result from the measurement or estimation of these values, some of them are often included in the calibration process, allowing

\begin{tabular}{|l|c|c|c|c|}
\hline \multicolumn{5}{|c|}{ TABLE 2 } \\
Characteristics of the rainfall events used in the \\
present study
\end{tabular}

\begin{tabular}{|l|l|l|c|c|c|}
\hline \multicolumn{7}{|c|}{ Sampling and measuring programme } \\
\hline Date & Condition & Type of measurement & $\begin{array}{c}\text { Duration } \\
\text { (hh:mm) }\end{array}$ & $\begin{array}{c}\text { Taking of } \\
\text { samples }\end{array}$ & $\begin{array}{c}\text { Number of } \\
\text { samples }\end{array}$ \\
\hline 27-02-01 & Rain & Hyetograph, hydrograph, pollutographs & $23: 00$ & Every hour & 23 \\
\hline 13-03-01 & Dry weather & Hydrograph, pollutographs & $25: 20$ & Every $100 \mathrm{~m}^{3}$ & 19 \\
\hline $28-03-01$ & Dry weather & Hydrograph, pollutographs & $23: 28$ & Every $75 \mathrm{~m}^{3}$ & 17 \\
\hline $06-04-01$ & Rain & Hyetograph, hydrograph, pollutographs & $12: 48$ & Every $65 \mathrm{~m}^{3}$ & 24 \\
\hline 30-04-01 & Rain & Hyetograph, hydrograph & $12: 00$ & & \\
\hline 08-05-01 & Dry weather & Hydrograph, pollutographs & $21: 53$ & Every $65 \mathrm{~m}^{3}$ & 23 \\
\hline 14-09-01 & Dry weather & Hydrograph, pollutographs & $17: 15$ & Every $45 \mathrm{~min}^{3}$ & 24 \\
\hline 20-11-01 & Dry weather & Hydrograph, pollutographs & $14: 00$ & Every hour & 15 \\
\hline
\end{tabular}


their variation in a rank to be considered appreciative. For the hydraulic calibration, a total of 11 calibration parameters were used, which are described in Table 4.

In the group of non-traditional parameters of calibration, width, slope and the impermeable area of the subcatchments were given separately. However, in the case of the streets, these parameters were kept fixed. The use of topographic maps with different scales may lead to error when estimating the area and width of the subcatchments. The subjectivity of this last parameter should be mentioned apart. Similarly, error is unavoidable when giving values from topographic maps to the slope of the subcatchments. With respect to the impermeable areas, it is difficult to determine which ones are directly connected to the combined sewer system or discharge their water on a permeable area.

The aims fixed for the calibration process for this study were:

- Hydrographs: peak flows and minimal flows with a difference of $30 \%$ against the measured values. Base time simulated with a maximum difference of ten minutes with respect to the measured hydrograph.

- Runoff volume: with a difference of a maximum of $10 \%$ with respect to the volume measured.

- Pluviographs: maximum and minimum concentration of the pollutant with a difference no greater than $30 \%$ against the measured values and with a maximum difference of ten minutes when they do appear. Total load of the pollutant with a difference no greater than $30 \%$ with respect to the total load measured.

The calibration was made by means of an iterative process of trial and error, by adjusting the parameters in Table 4 within the established range, and comparing (numerically and graphically) the hydrograph obtained in each simulation with the measured hydrograph, until a good fit was obtained between both and with respect to the pre-determined calibration aims.

The quality calibration is made by the hydraulic adjustment of the model. The SWMM gives four methods for the estimation of the dust and dirt accumulated in the catchment area. From these, the exponential method was chosen for this study, which is represented by Eq. (1). Besides, for each particular pollutant, the build-up was estimated as a fraction of dust and dirt:

$$
D D=D D L I M \cdot\left(1-e^{\text {DDPOW } \cdot t}\right)
$$

where:

$$
\begin{array}{ll}
\text { DD } & =\text { dust and dirt accumulated }(\mathrm{M}) \\
\text { DDLIM } & =\text { limit quantity of build-up (dimensionless) } \\
\text { DDPOW } & =\text { exponent (dimensionless) } \\
\mathrm{t} & =\text { dry weather period }(\mathrm{T})
\end{array}
$$

The wash-off is the transport of pollutants on the surface of a catchment area in a runoff period. The equation used by the SWMM allows the wash-off and every time step to be proportional to the runoff rate (r) raised to an exponent (WASPHO).

\begin{tabular}{|c|c|c|}
\hline \multicolumn{3}{|c|}{$\begin{array}{c}\text { TABLE } 4 \\
\text { Parameters used for the hydraulic calibration of the } \\
\text { model }\end{array}$} \\
\hline Parameters & $\begin{array}{c}\text { Rank of variation } \\
\text { allowed }\end{array}$ & $\begin{array}{l}\text { Initial } \\
\text { value } \\
\text { taken }\end{array}$ \\
\hline Average impermeable area & $\pm 10 \%$ & $17.7 \%$ \\
\hline Average width & $\pm 30 \%$ & $44.9 \mathrm{~m}$ \\
\hline Average slope & $\pm 30 \%$ & $13.1 \%$ \\
\hline \multicolumn{3}{|l|}{ Surface storage } \\
\hline Impermeable area & $0.3-2.5 \mathrm{~mm}^{*}$ & $1.0 \mathrm{~mm}$ \\
\hline Permeable area & $2.5-5.1 \mathrm{~mm}^{* *}$ & $2.0 \mathrm{~mm}$ \\
\hline \multicolumn{3}{|l|}{ Infiltration equation of Horton } \\
\hline Maximum infiltration, $\mathrm{f}_{0}\left(\mathrm{~L} \cdot \mathrm{T}^{-1}\right)$ & $25-75 \mathrm{~mm}^{*}$ & $25 \mathrm{~mm}$ \\
\hline Minimum infiltration, $\mathrm{f}_{c}\left(\mathrm{~L} \cdot \mathrm{T}^{-1}\right)$ & $0.0-10 \mathrm{~mm} *$ & $1.0 \mathrm{~mm}$ \\
\hline Decay coefficient, $\mathrm{k}\left(\mathrm{T}^{-1}\right)$ & $0.00056-0.00139 * \mathrm{~s}^{-1}$ & $0.00115 \mathrm{~s}^{-1}$ \\
\hline \multicolumn{3}{|c|}{\begin{tabular}{|l|l} 
Manning's roughness coefficient \\
\end{tabular}} \\
\hline Permeable area & $0.02-0.45^{*}$ & 0.10 \\
\hline Impermeable area & $0.010-0.015^{*}$ & 0.012 \\
\hline Pipes & $0.011-0.013^{* *}$ & 0.013 \\
\hline
\end{tabular}

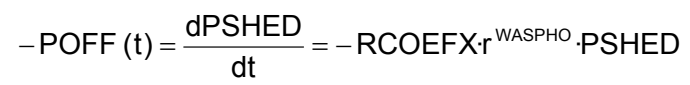

where:

$$
\begin{aligned}
\text { POFF }= & \text { load of pollutant washed-off in time } t\left(M \cdot T^{-1}\right) \\
\text { PSHED }= & \text { quantity of pollutant available for the } \\
& \text { wash-off in the time } t(M) \\
\text { RCOEFX }= & \text { wash-off coefficient }
\end{aligned}
$$

\begin{tabular}{|c|c|c|c|c|c|}
\hline \multicolumn{6}{|c|}{$\begin{array}{c}\text { TABLE 5 } \\
\text { Distribution of particle sizes of each pollutant } \\
\text { (Temprano, 1996) }\end{array}$} \\
\hline \multicolumn{2}{|c|}{ SS } & \multicolumn{2}{c|}{ COD } & \multicolumn{2}{c|}{ TKN } \\
\hline $\begin{array}{c}\% \\
\text { Superior }\end{array}$ & $\begin{array}{c}\text { Size } \\
(\mathbf{m m})\end{array}$ & $\begin{array}{c}\% \\
\text { Superior }\end{array}$ & $\begin{array}{c}\text { Size } \\
(\mathbf{m m})\end{array}$ & $\begin{array}{c}\% \\
\text { Superior }\end{array}$ & $\begin{array}{c}\text { Size } \\
(\mathbf{m m})\end{array}$ \\
\hline 100 & 0 & 100 & 0 & 100 & 0 \\
\hline 58 & 0.25 & 58 & 0.1 & 25 & 0.25 \\
\hline 31 & 0.83 & 43 & 0.25 & 15 & 0.83 \\
\hline 24 & 2 & 7 & 2 & 9 & 2 \\
\hline 0 & 15 & 0 & 3 & 0 & 3 \\
\hline
\end{tabular}

$$
\begin{aligned}
\text { WASPHO } & =\text { coefficient } \\
\mathrm{r} & =\text { runoff rate }\left(\mathrm{L} \cdot \mathrm{T}^{-1}\right)
\end{aligned}
$$

For the estimation of sedimentation and resuspension, each pollutant is given a specific gravity and a distribution of sizes of particles, which are applied during the whole route through the system. If the specific gravity is lesser or equal to 1.0 , the pollutant is considered to be in suspension or dissolved and not available for sedimentation and subsequent resuspension. For each pipe, the critical diameter of particle is estimated, taking into account the velocity, roughness and the specific gravity of the pollutant. In Table 5, the distribution of sizes of particles used for this study is shown (Temprano, 1996). The specific gravity for SS was 2.65, and for COD and TKN it was 1.1. These values were taken as fixed data and were not used as calibration parameters.

The flows during dry weather, which are entered in the runoff block for each subcatchment, were determined from the data measured during the five sampling campaigns, which were carried out during dry weather (see Tables 3 and 8).

The values of mean concentration of each pollutant that were used are the following: 100,300 and $20 \mathrm{mg} / \ell$ for SS, COD and TKN respectively, which were also determined in the measuring campaigns mentioned before.

Before starting the simulation of a rainfall event, the transport block of the program carries out a routine which estimates 
the mass of material deposited in the combined sewer system, depending on the number of previous dry weather days (DWDAYS). This estimation is made from a clean bed. For this study, an analysis of the sensitivity of the parameter DWDAYS was carried out with respect to the total load of simulated pollution, and a low level of sensitivity was found, which could be understood by taking into account the steep slope of the combined sewer system in the catchment area, which causes a low sedimentation. In the same way, it was verified how much of the build-up on the surface of the catchment area could be just before the rainfalls that were used for the calibration and validation. For this, the data which correspond to an exponential curve of dust and dirt in an urban area were entered and the rainfalls before the calibration and validation were simulated. It was observed that they caused a wash-off of the surface dirt of $70 \%$ and $60 \%$ respectively. Therefore, the equivalent time which caused a build-up similar to the remainder was sought. From the mentioned curve, on a dry weather day, a build-up superior to $50 \%$ of the maximum value that can be reached is obtained.

Five parameters were used for the quality calibration: DDLIM, DDPOW, RCOEF, WASPHO and QFAC(1). This last one represents the fraction of each pollutant with respect to the total dust and dirt. These parameters were varied individually and by means of combinations of them, until obtaining good agreement between the output of the model and that measured with respect to total pollutant load in the rainfall, peak concentrations and general tendency of the pluviograph.

\section{Validation}

The parameters obtained in the calibration process were used to simulate two independent rainfall events. The rainfall event of 30-04-01 was used for the hydraulic validation, and the rainfall event of 27-02-01 was used for quality and hydraulic validation.

\section{Results and discussion}

\section{Hydraulic calibration}

The final values obtained for the parameters in the calibration are shown in Table 6.

The order in which the parameters appear in Table 6 also corresponds to the order in which they were adjusted during the calibration, and to their sensitivity during the simulation of the hydrographs. The percentage of impermeable surface area turned out to be the most sensitive parameter, presenting

\begin{tabular}{|l|c|}
\hline \multicolumn{2}{|c|}{$\begin{array}{c}\text { TABLE } 6 \\
\text { Parameters obtained in the hydraulic calibration of } \\
\text { the model }\end{array}$} \\
\hline Parameters & $\begin{array}{c}\text { Value obtained in the } \\
\text { calibration }\end{array}$ \\
\hline Average impermeable area & $15.9 \%$ \\
\hline Average width & $31.4 \mathrm{~m}$ \\
\hline Average slope & $9.2 \%$ \\
\hline Surface storage \\
\hline Impermeable area \\
Permeable area & $2.5 \mathrm{~mm}$ \\
\hline Infiltration equation of Horton & $5.0 \mathrm{~mm}$ \\
\hline Maximum infiltration, $\mathrm{f}_{0}\left(\mathrm{~L} \cdot \mathrm{T}^{-1}\right)$ & $38 \mathrm{~mm}$ \\
Minimum infiltration, $\mathrm{f}_{\mathrm{c}}\left(\mathrm{L} \cdot \mathrm{T}^{-1}\right)$ & $2.5 \mathrm{~mm}$ \\
Decay coefficient, $\mathrm{k}\left(\mathrm{T}^{-1}\right)$ & $0.00115 \mathrm{~s}^{-1}$ \\
\hline Manning's roughness coefficient \\
\hline Permeable area & 0.40 \\
Impermeable area & 0.015 \\
Pipes & 0.015 \\
\hline
\end{tabular}

a strong influence on the total volume of runoff and the peak flows. Slope, width and the Manning's roughness coefficient had an influence on the time of presentation of the peak flows. To obtain a good adjustment of the hydrograph, the initial percentage of impermeable surface area was decreased $10 \%$, the width was decreased $30 \%$ and also the slope $30 \%$ for each subcatchment. These are reasonable values when taking into account the error margin that can be obtained when estimating these parameters. Ovbiebo and She, (1995) using a module of automatic calibration for SWMM, got reductions with respect to the initial value, which ranged between 5 and $25 \%$ for the impermeable area and $8 \%$ for width of the subcatchments. The parameters of surface storage, infiltration and roughness were adjusted within the range of the established values in the literature.

The parameters of the hydraulic adjustment, which were obtained in the calibration of the rainfall of 06-04-01, were used with an independent rain with the purpose of validating the model. The result can be seen in Fig. 2.

The calibrated model adjusted with accuracy all the variations in the measured flow. The simulated peak flows are on average $20 \%$ greater than the ones measured, and the adjustment in time is quite accurate, so a maximum difference of $5 \mathrm{~min}$ between both of them is obtained. With respect to this, Ovbievo and She (1995) got an error of $25 \%$ in the values of the peak flows that were simulated during a process of validation of the SWMM
Figure 2 Simulation of the hydrograph for the rainfall event of 30-04-01

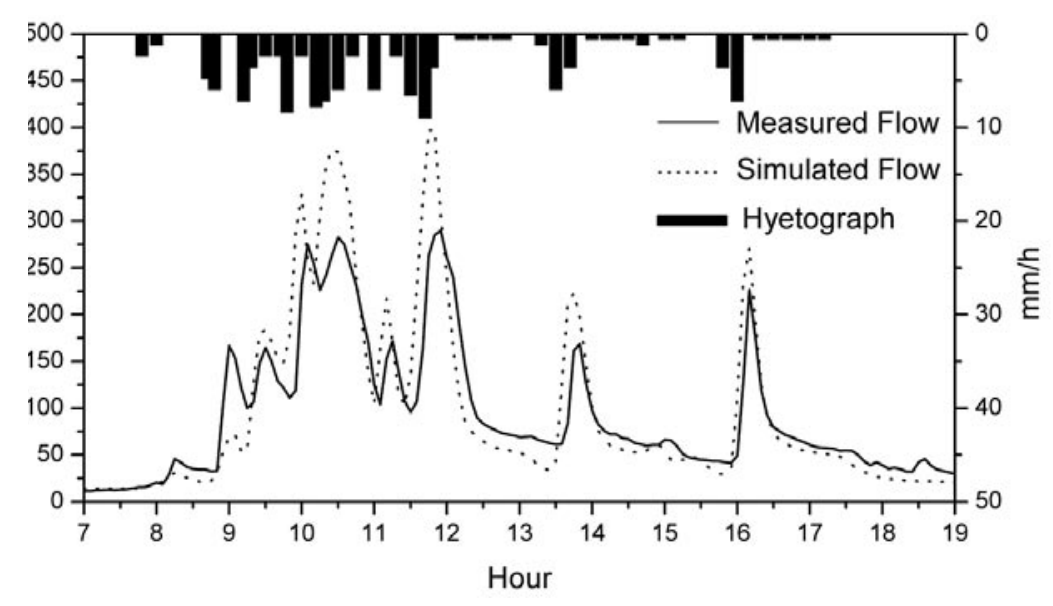


with three different rainfalls. The possible errors during the measurement of the flows must also be taken into account. Maksimovic (1986) estimated an uncertainty level of between 5 and $25 \%$ in the measurement of the flows, depending on the method that was used. The runoff block of the SWMM model, version $4.4 \mathrm{~h}$, does not allow the input of peak coefficients for the time variations during dry weather flow. Therefore, the fluctuations in the total flow that are obtained due to these variations cannot be taken into account in the simulation. The result of this failure of the model is evident in the low points of the hydrograph. With respect to the total volumes, a difference of only $4 \%$ between the simulated volume and the measured one was obtained; the first one was the greatest. In general, the hydraulic prediction is good, considering a very long rainfall with a very variable intensity.

\section{Quality calibration}

In Figs. 3, 4 and 5, the quality calibration with the rainfall event of 06-04-01 for SS, COD and TKN respectively is presented. The adjustment obtained for the values of peak concentrations among the measured and simulated pollutants was quite accurate and the moment of the prediction presents a difference, which is less than five minutes with respect to the moment of the measurement. A good adjustment in the low points of the pluviographs was obtained, as well as in the initial and final values of them. As for the total loads of pollution measured and simulated at the end of the rainfall, an approximation of $94 \%$, $96 \%$ and $85 \%$ was obtained for SS, COD and TKN respectively. It has been verified that it is possible to get a good adjustment of the variations of each pollutant in the course of the rainfall by an adequate modification of the parameters that the program gives.

The quality validation of the model was made with the rainfall of 27-02-01, and as a result, an adjustment was obtained between the simulated loads and the measured loads of $93 \%$, $95 \%$ and $78 \%$ for SS, COD and TKN respectively, which confirms the good capacity of the model for prediction.

The parameters of Eqs.(1) and (2) obtained in the calibration of the model are shown in Table 7.

By using Eq. (1), in the case of the streets, an accumulation of dust and dirt of $46 \mathrm{mg} / \mathrm{km}$ of curb and day is obtained, slightly higher than the rank of 25 to $42 \mathrm{~kg} / \mathrm{km}$ per curb/day obtained by Cano (1996) for the city of Santander, and also higher than the values given by Huber and Dickinson (1988) for the case of a catchment in urban areas (17 to $43 \mathrm{~kg} / \mathrm{km}$ per curb/day). Although the values of the obtained parameters in the calibration of the model can be similar to the measured values, they are not supposed to be representative of the dust accumulation and real build-up, since it is only a way of adjusting the polluting load which is simulated with the measured load at the exit of the catchment area. According to the studies of Ashley et al. (1994), Gromaire-Mertz et al. (1998 and 2001) and Chebbo et al. (2001), most of the polluting load of the flows in combined sewers during rainy weather, originates inside the combined sewer system. In addition, the same authors have also shown that the particles found at the exit of the combined sewer system, are fine and have a high percentage of organic matter whereas the particles in the sedimentation storages are larger and mainly inorganic.

For the case of the subcatchments, an accumulation of $17.5 \mathrm{~kg} /$ ha dust and dirt is obtained when entering the parameters calibrated in Eq. (1). Reported values for this parameter were not found in the literature because generally in those SWMM studies where quality simulation has been made, it is normal to take

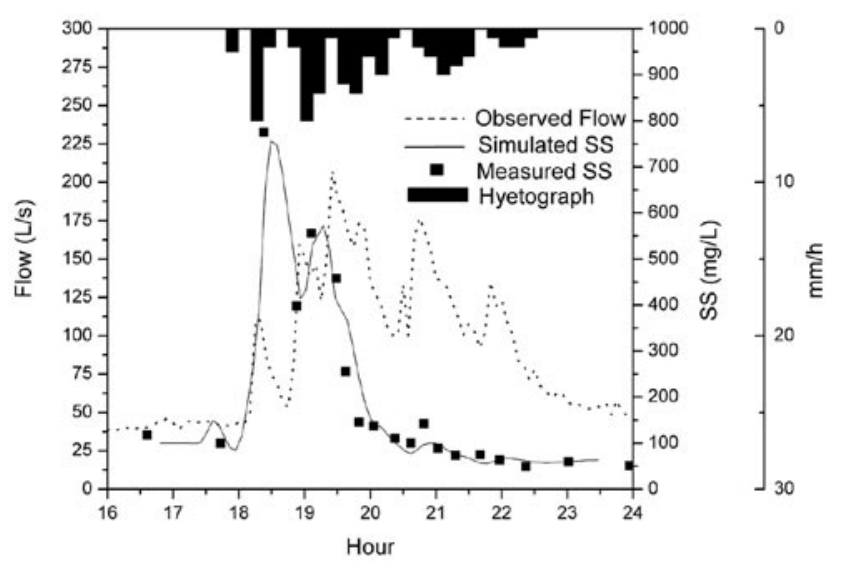

Figure 3

Calibration of the SS with the rainfall event of 06-04-01

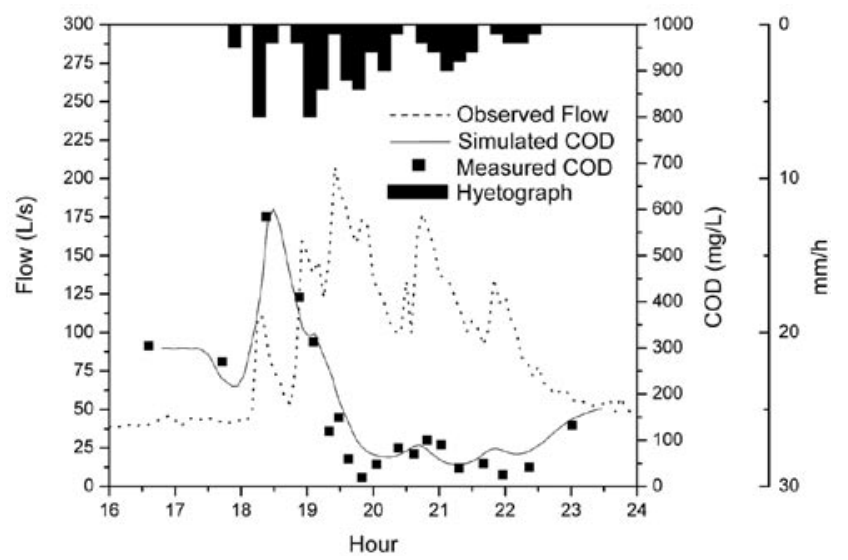

Figure 4

Calibration of the COD with the rainfall event of 06-04-01

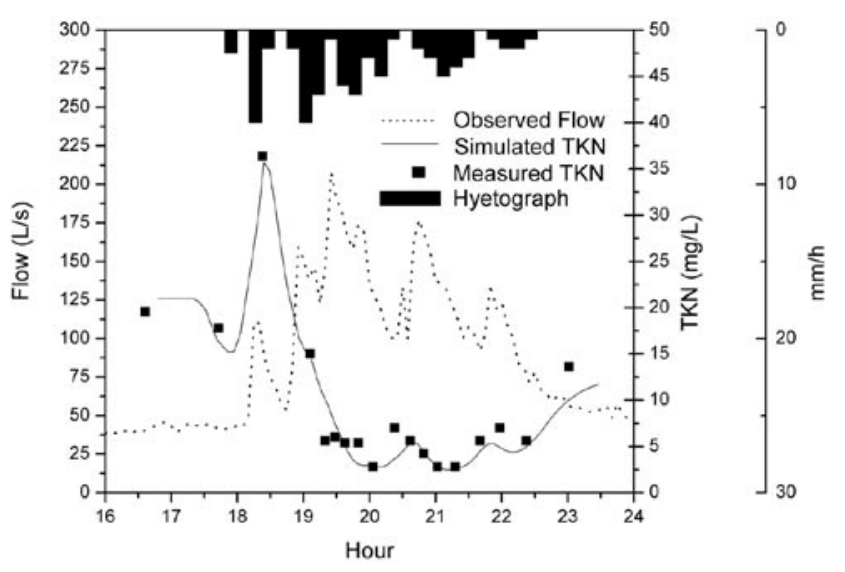

Figure 5

Calibration of TKN with the rainfall event of 06-04-01

\begin{tabular}{|l|l|l|l|}
\hline \multicolumn{4}{|c|}{$\begin{array}{c}\text { TABLE 7 } \\
\text { Parameters of the equations of build-up } \\
\text { and wash-off }\end{array}$} \\
\hline & DDLIM & DDPOW \\
\hline Subcatchments: & $17.5 \mathrm{~kg} / \mathrm{ha} \cdot \mathrm{d}$ & 0.3 \\
\hline Streets: & $46 \mathrm{~kg} / \mathrm{km} \mathrm{curb} \cdot \mathrm{d}$ & 0.3 \\
\hline & QFAC1 & WASPHO & RCOEF \\
\hline SS & $200 \mathrm{mg} / \mathrm{g}$ & 1 & 46 \\
\hline COD & $58 \mathrm{mg} / \mathrm{g}$ & 1 & 100 \\
\hline TKN & $2.2 \mathrm{mg} / \mathrm{g}$ & 1 & 220 \\
\hline
\end{tabular}


into account only the build-up in the streets, disregarding the build-up in other runoff sources, such as roofs and courtyards. With respect to this, Gromaire-Mertz et al. (2001) found that the polluting load of the runoff in the streets, as for SS, COD and BOD, represent on average only $56 \%, 57 \%$ and $58 \%$ respectively of the total pollution of the runoff.

As for the parameter QFAC1, a value of $58 \mathrm{mg} \mathrm{COD} / \mathrm{g}$ of dust and dirt was obtained for the COD, which is found within the rank of 24.6 - $61.3 \mathrm{mg} / \mathrm{g}$ given by Huber and Dickinson (1988) for urban catchment areas, which is quite close to the upper limit of the intervals of 45.9 to $54.6 \mathrm{mg} / \mathrm{g}$ measured by Cano (1996) for Santander. In the case of TKN, although it was used for the calibration, it was above the range of 0.73 to $1.8 \mathrm{mg} / \mathrm{g}$ presented by Huber and Dickinson (1988), and the total load simulated was in fact $22.6 \%$ smaller than the measured one. Finally, if it is considered that the SS corresponds $100 \%(1000 \mathrm{mg})$ to dust and dirt, the value of the fraction taken for the SS corresponds to $20 \%$ of these. No values were found in the literature with respect to this parameter; however, Domínguez et al. (2001) found an average relationship of $18 \%$ between TSS and SS in combined sewer system flow.

\section{Pollution of the wastewater in rainy weather}

The concentration ranges and the event mean concentration (EMC) of SS, COD and TKN measured at the exit of the catchment area during the two rainfalls analysed and the concentration of the flow during dry weather are shown in Table 8 .

The concentration ranges of pollutants obtained during the rainfalls are comparable to those found in the literature (Gromaire-Mertz et al., 2001; Lee and Bang, 2000), and the average concentration in dry weather corresponds to urban wastewater of weak concentration (Henze et al, 1995). The upper limits of the range for the three pollutants were measured during the initial phase of both rainfall events, whereas the lower limits were measured at the end of them, which could indicate the happening of a first flush.

In most cases, these lower limits were very low if they are compared to the values in the literature, which can be explained by the fact that the studied catchment area has a low population density and a weak concentration of pollutants in dry weather. Therefore, when flows during the rain take place - up to ten times greater than those during dry weather - dilutions in the same order of magnitude are obtained. In Table 8 , it is also observed that during the rainfalls, pollution peaks were produced. These were much higher than those flows in dry weather, especially for the case of SS, which confirms the great polluting level that the mixed flows can contain in combined sewer systems.

\section{The effect of the first flush}

The first flush can be defined as the initial period of the runoff, during which the concentration of pollutants is considerably higher than those measured with passing time (Gupta and Saul, 1996). For its analysis, the accumulated fraction of the pollutant against the accumulated fraction of the volume of rain is presented. If the presented data are above a $45^{\circ}$ line, it is considered that there is a first flush and its incidence can be quantified depending on the grade of separation with respect to the line of 45 degrees (Geiger, 1987; Gupta and Saul, 1996). Other researchers (Saget et al., 1996; Bertrand-Krajewski et al., 1998) suggest that there is a first flush only if at least $80 \%$ of the polluting load is carried in the first $30 \%$ of the volumes. Lee et al. (2002) consider that the previous definition would mean that the phenomenon would only be caused in $1 \%$ of the events. Deletic (1998) considers that a first flush in a rainfall is presented if a percentage of polluting load, greater than $20 \%$, is carried by the first $20 \%$ of volume. Lee and Bang (2000) are of the opinion that the first flush takes place if the curve of the fraction of polluting load accumulated is above the curve of the fraction of accumulated volume.

For this study, the fact that a first flush takes place when the curve of the accumulated fraction of pollutant is above the accumulated fraction of volume has been taken into account, with its intensity being measured depending on the fraction of the polluting load swept along by the first $30 \%$ of the volume. In Figs. 6 and 7, the curves of accumulated fraction of pollutant are presented, against the accumulated fraction of volume for SS, COD and TKN for the rainfall events on the days of 06-04-01 and 27-02-01 respectively. In every case, except for the TKN curve for the rainfall of 27-02-01, clear deviations are seen with respect to the line of $45^{\circ}$. For the rainfall of $06-04-01,65 \%, 57 \%$ and $54 \%$ of the polluting loads of COD, SS and TKN respectively were swept by the first $30 \%$ of the volume, whereas in the rainfall of 27-02-01, the same fraction of volume swept $60 \%, 45 \%$ and $30 \%$ of the loads of COD, SS and TKN respectively.

Gupta and Saul (1996) showed that in combined sewer systems, the pollution load of the first flush of SS correlates well with the intensity of the rainfall, the duration and the dry-weather period, whereas Saget et al. (1996) did not find any relationship between the phenomenon of the first flush and the characteristics of the catchment area (area, time of concentration and slope) and neither did they find a relationship between the characteristics of the rainfall (total volume, intensity and dry weather period). As for the above-mentioned, the results obtained from this study are contradictory with respect to the ones obtained by Gupta and Saul (1996), since despite the fact that both rainfall events have practically the same period of dry weather, and that the rainfall of 27-02-01 was more intense than the first one, the first flush effect that was observed was greater in the rainfall of 06-04-01. The explanation could be found in the way the samples were taken during both rainfall events: in the event of 06-04-01 a sampling procedure according to the flow was used, in the event of 27-02-01 the sampling procedure was proportional to the time (each hour).

\begin{tabular}{|l|c|c|c|c|c|c|}
\hline \multicolumn{7}{|c|}{ TABLE 8 } \\
Concentration of pollutants in dry and rainy weather \\
\hline Parameter & Event of 06-04-01 & Event of 27-02-01 & \multicolumn{2}{c|}{ Dry weather } \\
\cline { 2 - 7 } & Range & EMC* $^{*}$ & Range & EMC* $^{*}$ & Range & AC** $^{* *}$ \\
\hline SS $(\mathrm{mg} / \ell)$ & $35-775$ & 214 & $5-179$ & 71.4 & $58-170$ & 100 \\
\hline COD $(\mathrm{mg} / \ell)$ & $20-584$ & 157 & $20-216$ & 85.9 & $180-498$ & 297 \\
\hline TKN $(\mathrm{mg} / \ell)$ & $2.8-36.4$ & 10.4 & $2.8-19.6$ & 6.5 & $16.2-20.2$ & 18.8 \\
\hline *EMC: Event Mean Concentration \\
**AC: Average Concentration proportional to the flow \\
\hline
\end{tabular}




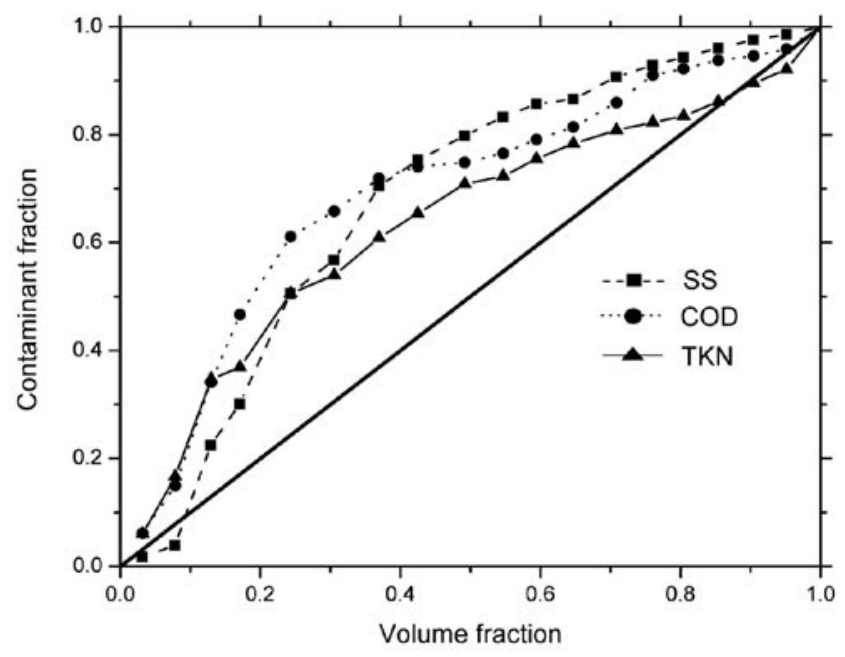

Figure 6

Curves of accumulated load for the rainfall event of 06-04-01

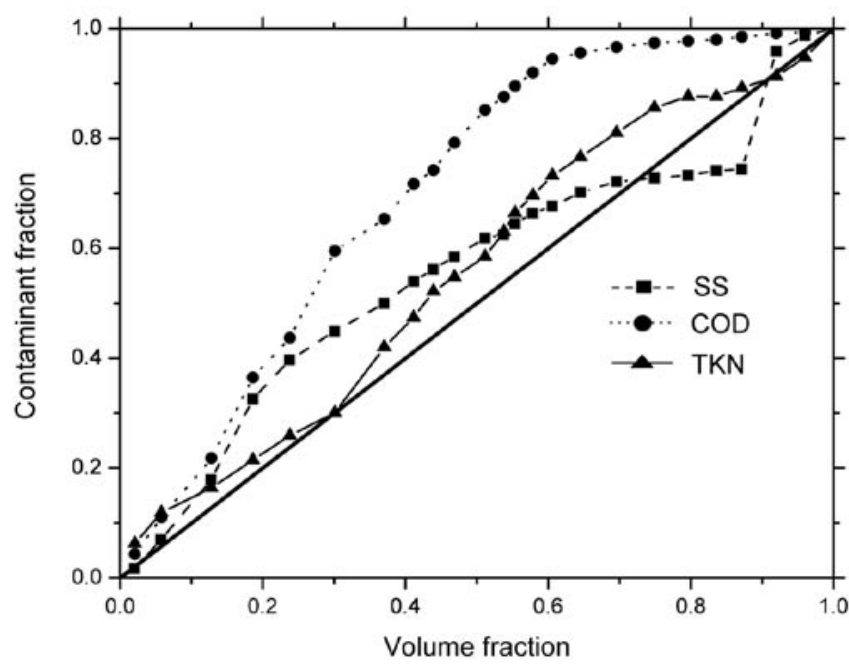

Figure 7

Curves of accumulated load for the rainfall event of 27-02-01

\section{Conclusions}

After the calibration of the SWMM model to simulate the flows and the polluting loads during rainy weather in the combined sewer system at the exit of a catchment area in the city of Santander, the following general conclusions can be drawn:

- The results obtained show the considerable predictive capability of the SWMM model when it is correctly calibrated from measured data. For the hydraulic validation, a very accurate adjustment in terms of time and variation of flows was obtained, and the total volume simulated presented only a difference of $4 \%$ with respect to the measured volume. As for the quality validation, the accuracy of the adjustment among the total loads of SS, COD and TKN, measured and simulated at the end of the rainfall, was $93 \%, 95 \%$ and $78 \%$ respectively.

- The phenomena of build-up, scour and transport of pollutants in combined sewer systems are influenced by a large number of variables, and their dynamics are still not wellknown. That is why simulation models like the SWMM do not take into account some of the peculiarities of these phenomena. As previously stated, this indicates the need to calibrate the model from real measurements whenever quality simulations have to be made for a specific area.

- First flush was observed in the rainfall events analysed, accounting for $65 \%$ of the COD load and $57 \%$ of the SS load during the first $30 \%$ of the volume of mixed flows for the rainfall event of 06-04-01. However, in the rainfall event of 27-02-01, despite having greater intensity, the effect of the first flush observed was smaller, which was attributed to the fact that the sampling was done in periods of one hour, showing the need to take frequent samples at the start of the rainfall event in order to record the phenomenon with better accuracy.

\section{Acknowledgements}

This study was supported as part of the project 'Integral Adaptation of the Urban Sewer System in Santander to Rainy Weather" (1FD97-1360) funded by the Spanish Ministry of Education and Culture (National Plan of I + D) and the European Regional Development Fund.

Thanks also go to the Municipal Service of Water of Santander (SEMAS) for its collaboration in the fulfilment of the obligations of this study.

\section{References}

ALLEY RB and SMITH PE (1982) Distributed Routing Rainfall-Runoff Model: Version II. US Geological Survey.

ASHLEY RM, ARTHUR S, COGHLAN B and McGREGOR I (1994) Fluid sediment in combined sewers. Water Sci. Technol. 29 (1-2) 113-123.

BERTRAND-KRAJEWSKI J J, CHEBBO G and SAGET A (1998) Distribution of pollutant mass vs. volume in stormwater discharges and the first flush phenomenon. Water Res. 32 (8) 2341-2356.

CANO AJ (1996) Contaminación de la escorrentía superficial en un área metropolitana de la ciudad de Santander. Master's Thesis. Department of Ciencias y Técnicas del Agua y del Medio Ambiente. University of Cantabria. Spain. In Spanish.

CHARACKLIS GW and WIESNER MR (1997) Particles, metals and water quality in runoff from large urban watershed. J. Environ. EngASCE 123 (8) 753-759

CHARBENEAU RJ and BARRETT ME (1998) Evaluation of methods for estimating stormwater pollutant loads. Water Environ. Res. $\mathbf{7 0}$ (7) $1295-1302$.

CHEBBO G, GROMAIRE-MERTZ MC, AHYERRE M and GARNAUD S (2001) Production and transport of urban wet weather pollution in combined sewer systems: the Marais experimental urban catchment in Paris. Urban Water 3 (1-2) 3-15.

CRISTINA CM and SANSALONE JJ (2003)"First flush," power law and particle separation diagrams for urban storm-water suspended particulates. J. Environ. Eng-ASCE 129 (4) 298-307.

DANISH HYDRAULIC INSTITUTE (1990) MOUSE User's Manual.

DELETIC A (1998) The first flush load of urban surface runoff. Water Res. 32 (8) 2462-2470.

DIAZ-FIERROS TF, PUERTA J, SUAREZ J and DIAZ-FIERROS VF (2002) Contaminant loads of CSOs at the wastewater treatment plant of a city in NW Spain. Urban Water 4 (3) 291-299.

DOMÍNGUEZ Y, GARCÍA-MORALES JL and QUIROGA JM (2001) Caracterización de las aguas residuales de aporte a una EDAR. Ing. Quim. 33 (375) 135-141.

GEIGER W (1987) Flushing effects in combined sewer systems. Proc. 4th Int. Conf. on Urban Storm Drainage. Lausanne, Switzerland. 40-46.

GROMAIRE-MERTZ MC, CHEBBO G and SAAD M (1998) Origins and characterization of urban wet weather pollution in combined sewer system: the experimental urban catchment "Le Marais" in Paris. Water Sci. Technol. 37 (1) 1-8. 
GROMAIRE-MERTZ MC, GARNAUD S and SAAD M (2001) Contribution of different sources to the pollution of wet weather flows in combined sewers. Water Res. 35 (2) 521-533.

GUPTA K and SAUL AJ (1996) Specific relationships for the first flush load in combined sewer flows. Water Res. 30 (5) 1244-1252.

HENZE M, HARREMOËS P, JANSEN J and ARVIN E (1995) Wastewater Treatment. Springer Verlag, Germany.

HUBER W and DICKINSON R (1988) Stormwater Management Model. Version 4, Part A. User's Manual. U.S. Environmental Research Agency. Office of Research and Development. EPA/600/3-88/001a.

HUBER W (1992) Contaminant transport in surface water. In: Maydment DR (ed.) Handbook of Hydrology. McGraw-Hill, New York.

HYDROLOGIC ENGINEERING CENTER (1997) Storage, Treatment, Overflow, Runoff Model, STORM. Hydrologic Engineering Center, US Corps of Engineers, Davis, California, USA.

LEE JH and BANG KW (2000) Characterization of urban stormwater runoff. Water Res. 34 (6) 1773-1780.

LEE JH, BANG KW, KETCHUM LH, CHOE JS and YU MJ (2002) First flush analysis of urban storm runoff. Sci. Total Environ. 293 (1-3) 163-175.

LIONG SY, CHAN WT and LUM LH (1991) Knowledge-based system for SWMM runoff component calibration. J.Water Res. Pl-ASCE 117 (5) 507-523.

MAKSIMOVIC R (1986) Urban Drainage Catchments: Selected Worldwide Rainfall-Runoff Data from Experimental Catchments. Pergamon Press, Belgrade.
NOVOTNY V and OLEM H (1994) Water Quality. Prevention, Identification, and Management of Diffuse Pollution. Van Nostrand Reinhold, New York.

OVBIEBO T and SHE N (1995) Urban runoff quality modeling in a subbasin of the Duwamish River using XP-SWMM. Proc. Watershed Management Symposium Held in San Antonio, Texas, USA. August 14-19. ASCE, New York. 320-329.

SAGET A, CHEBBO G and BERTRAND JL (1996) The first flush in sewer systems. Water Sci. Technol. 33 (9) 101-108.

STANDARD METHODS (1998) Standard Methods for the Examination of Water and Wastewater (20 ${ }^{\text {th }}$ edn.). American Public Health Association, American Water Works Association and Water Environment Federation. APHA, AWWA and WEF

TEMPRANO J (1996) Criterios de dimensionamiento de depósitos de tormenta para Santander. Doctoral Thesis. Department of Ciencias y Técnicas del Agua y del Medio Ambiente. University of Cantabria, Spain. In Spanish.

TEMPRANO J and TEJERO I (2002) Detention storage volume for combined sewer overflow into a river. Environ. Technol. 23 (6) 663 675.

TSIHRINTZIS V and HAMID R (1998) Runoff quality prediction from small urban catchments using SWMM. Hydrol. Process. 12 (2) $311-329$.

ZOPPOU C (2001) Review of urban storm water models. Environ. Modell. Softw. 16 (3) 195-231. 